\title{
РЕФОРМИРОВАНИЕ РЕГИОНАЛЬНОЙ ТОРГОВЛИ: КОЛЛЕКТИВИЗАЦИЯ ПОТРЕБЛЕНИЯ
}

\author{
Ю. В. Мятишкин
}

Институт проблем управления сложными системами Российской академии наук обособленное подразделение Федерального государственного бюджетного учреждения науки Самарского федерального исследовательского центра Российской академии наук, г. Самара, Россия myat_yv@mail.ru

Сегодняшняя проблема распространения коронавирусной инфекции предъяила новые требования к организации экономики. Как сохранить жизнеспособность народного хозяйства при условии резкого сокращения личных контактов людей во избежание передачи заболевания? Как обеспечить инвестиционную активность в условиях карантина, чтобы свести к минимуму неэффективное расходование бюджетных денег?

Современные телекоммуникационные средства во многом позволяют разрешить противоречие сохранения экономических связей и отсутствия личных контактов. Однако далеко не все хозяйственные задачи можно решить по телефону и в сети Интернет. Физическая передача товаров, в первую очередь, продуктов питания, а также личные перемещения на общественном транспорте создают очаги для массового распространения инфекции.

Организация совместных покупок жильцами многоквартирных домов на основе развитой до необходимого уровня системы местного самоуправления позволит не только реализовать безопасное снабжение всех граждан и добиться более высокой степени самоизоляции, но и организовать эффективное управление карантинными ограничениями на местном уровне. При этом помимо противодействия распространению инфекции посредством модернизированной потребительской кооперации можно получить новый импульс развития экономики.

Ключевые слова: карантин, самоизоляция, потребительская кооперация, самоуправление, совместные покупки, супермаркеты, магазины, розничная торговля, городской транспорт. 


\title{
THE REFORM OF REGIONAL TRADE: COLLECTIVIZATION OF CONSUMPTION
}

\author{
Y. V. Myatishkin \\ Institute for the Control of Complex Systems of the Russian Academy of Sciences, Samara, \\ Russia \\ myat2004@mail.ru
}

The current problem of coronavirus infection dissemination caused new requirements for the organization of the economy. How can the viability of the national economy be maintained if people's personal contacts are drastically reduced in order to avoid infection? How to ensure investment activity in a quarantined environment in order to minimize inefficient budget money spending?

Modern telecommunication tools allow us to a large extent to solve the contradiction between maintaining economic ties and the absence of personal contacts. However, not all economic objectives can be solved by phone and on the Internet. The physical transfer of goods, primarily food, as well as personal movements on public transport, create hotbeds for the mass dissemination of infection.

The organization of joint shopping by residents of apartment buildings on the basis of well-developed system of local self-government will not only ensure the safe supply of all citizens and help to achieve higher degree of self-isolation, but also will facilitate effective management of quarantine restrictions at the local level. At the same time, in addition to countering the dissemination of infection through modernized consumer cooperation, it is possible to get a new impetus for the development of the economy.

Keywords: quarantine, self-isolation, consumer cooperation, self-government, joint purchases, supermarkets, stores, retail trade, urban transport.

\section{ВВЕДЕНИЕ}

Сегодня мир столкнулся с новой вирусной угрозой, и большинство стран предприняли карантинные меры, при этом они были вынуждены разорвать многие экономические связи - как внутренние, так и международные. Это вызвало серьезные проблемы в экономике, причем далеко не всем странам предпринятые ограничения обеспечили возможность локализовать распространение инфекции до нулевого уровня ее распространения, а значит, нужны дополнительные или иные меры.

Доступные сегодня методы карантинной самоизоляции граждан, предназначенные для остановки или хотя бы ограничения распространения коронавирусной инфекции, оставляют возможность контактирования людей на 
работе в системообразующих предприятиях, в магазинах и в общественном транспорте. Очевидно, что те люди, которые сидят дома на самоизоляции, единственным местом, где они подвергаются угрозе заражения, являются магазины.

Для бизнеса магазина выполнение усиленных санитарных требований является дополнительными издержками, в них входят расходы на мощную вентиляцию помещений; усиленные меры санитарной обработки; маски и прочие индивидуальные средства защиты для сотрудников; организацию потока посетителей магазина, предотвращающую скученность людей и прочие меры, которые более характерны для содержания медицинских учреждений, чем торговых. Помимо этого, если не пускать в магазин людей без масок, а также осуществлять прочие строгости карантинных мер, то для продавцов это будет означать непосредственную потерю покупателей до того момента, пока в обществе не станет карантинных скептиков меньшинство. Поэтому усиленные санитарные нормы без внешнего принуждения руководителей в большинстве случаев не выполняются, а во многих магазинах не могут быть выполнены из-за отсутствия необходимых средств.

Такие личностные факторы, как психологическая защита (отрицание, непризнание существования реальной проблемы), низкий уровень солидарности граждан, правовой нигилизм, коррупция, невысокий уровень образованности для эффективной реализации самостоятельной защиты от инфекции себя и окружающих граждан играют отрицательную роль в реализации полноценной самоизоляции населения. Это делает невозможным эффективное подавление распространения инфекции как на ранней стадии возникновения, так и по мере ее распространения. K тому же, не у всех граждан есть возможность соблюдать необходимые правила.

Таким образом, принимаемые сегодня ограничительные меры не смогут обеспечить стопроцентное подавление распространения вирусной инфекции. Это значит, что она, хоть и замедленно, но продолжит распространяться в соответствии с экспоненциальной зависимостью.

В связи с этим, целесообразно закрыть все магазины как распространители инфекции для посещения розничными покупателями, организовав совместные кооперативные закупки для жильцов многоквартирных домов (МКД) и домов по соседству.

Магазин в этом случае превращается в логистический центр, а размещение товаров в потребительскую корзину (посылку) осуществляет сотрудник магазина. Далее совокупность посылок, предназначенных жильцам дома, должен забирать доставщик и развозить их по квартирам бесконтактным способом. На ментальной карте (рис.1) приведен анализ формирования данного способа реализации товаров без потери рабочих мест сотрудниками торговли и утраты возможности сбыта своих товаров магазинами.

Это кардинально снизит риск одновременного заражения большого числа людей, позволит лучше отследить цепочки заражения, если таковое при осуществлении снабжения произошло. 


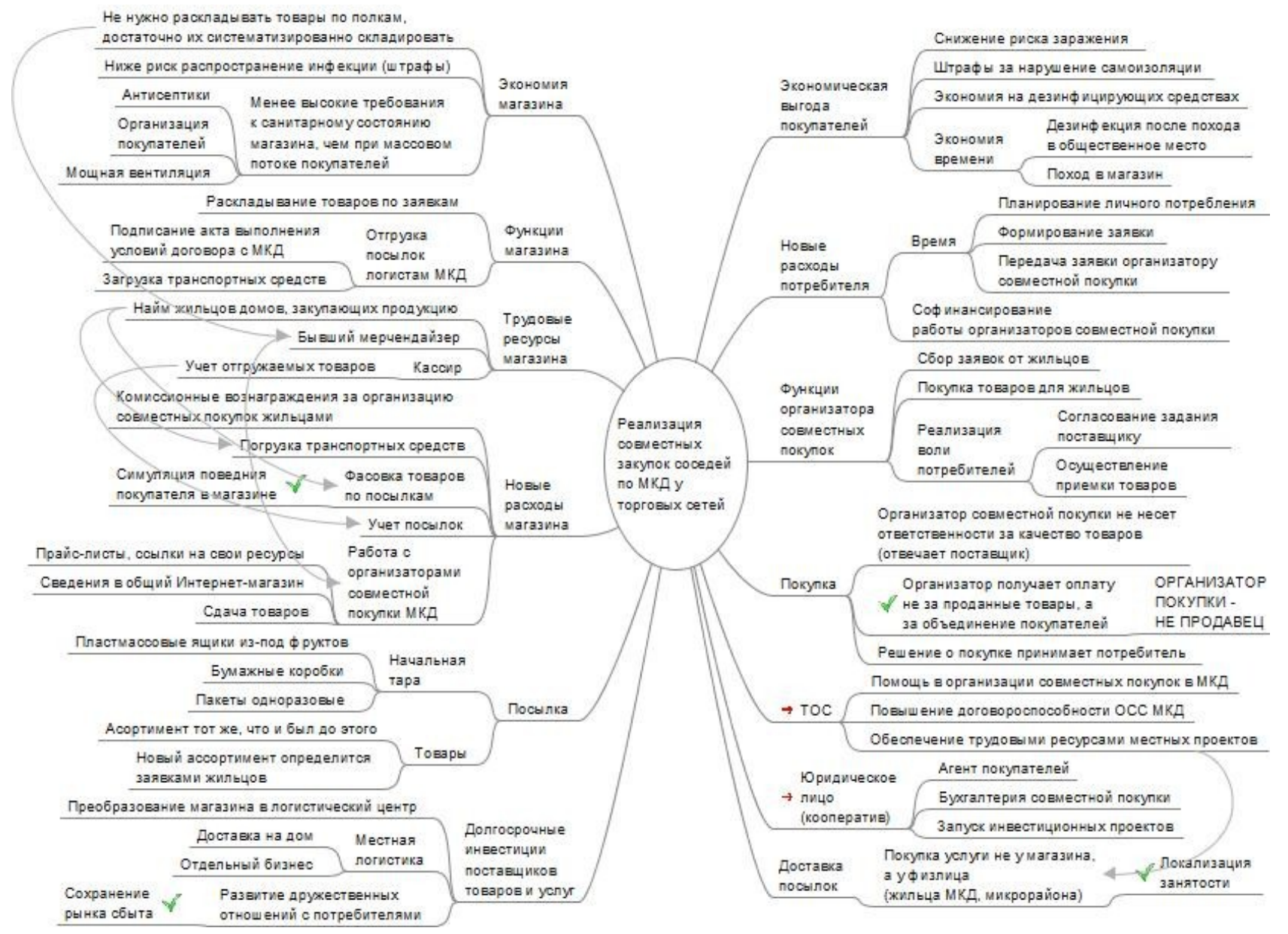

Галочками на рисунке обозначены комментарии

Рис. 1 Организация сбыта товаров супермаркетом потребительской кооперации

Помимо повышенного риска заражения коронавирусом (и прочей инфекцией) супермаркеты и другие магазины имеют множество других недостатков, которые можно решить кооперативным способом.

При этом если применять прежние подходы к потребительской кооперации, не выдержавшие конкуренции, то выполненные преобразования экономических отношений по окончании эпидемии будут отторгнуты обществом. А так как вирусная угроза навсегда не исчезнет из-за достаточно быстрого процесса эволюции микроорганизмов, то необходимо довести массовый дистанционный способ покупок до более конкурентоспособного состояния, чем сегодня.

\section{НЕДОСТАТКИ СОВРЕМЕННОЙ КООПЕРАЦИИ}

Основной мотив современных совместных покупок со времен появления первых эффективных потребительских кооперативов - это экономия денежных средств на большом объеме покупок [1]. Сообща достигается возможность осуществить приобретение товаров по оптовым ценам с меньшей наценкой, чем в розничной торговле. 
Однако сегодня крупные торговые сети превосходят по оптовым объемам любой вновь появившийся кооператив или легко сможет его превзойти, как только тот начнет расширяться.

Массовое кооперативное снабжение в мире возникло в середине 20-го века, оно потеснило лавочников, но далее его заместила система супермаркетов, которые входя в состав кооперативов, наравне с рядовыми членами участвовали в совместной закупке по оптовым ценам. Это дало возможность обеспечить для конечного потребителя сопоставимые цены с кооперативными [1].

Посещение кооперативной лавки - это не покупка, а получение предоплаченного товара. Такая форма отношений не предусматривает борьбу продавца за покупателя. Членам кооперативов нужно ходить на собрания, участвовать в коллективном хозяйстве. Всех этих сложностей и неудобств лишен супермаркет. Его преимуществом для потребителей по сравнению с кооперативами оказалось предоставление сервиса. K тому же, граждане получили больше возможностей одним походом в магазин удовлетворить максимально широкий набор своих потребностей.

При этом реализация совместных покупок (после длительного спада потребительской кооперации) получила новый импульс благодаря специализированным сайтам в сети Интернет. Здесь, в отличие от кооперативов, создание групп потребителей с общими интересами происходит стихийно, после покупки они, как правило, распадаются.

Данный способ торговли сразу выявил свои недостатки, в том числе неопределенность статуса организатора совместной покупки [2, 3]. Он является продавцом товаров или организатором сбора людей на их совместное приобретение? Организатору покупки выгодно быть аффилированным поставщиками агентом, а перед потребителями позиционироваться организатором сбора людей и распространения совместно приобретенного.

В результате нечеткой подотчетности организатора за результаты совместной покупки сделка совершается с неоднозначным для пользователя результатом. На сайте совместных покупок потребитель может получить товар, отличающийся от заказанного по размеру, цвету, цене (из-за того, что заранее невозможно оценить все издержки). Далее потребитель вынужден решать, как с полученным товаром обращаться - «пристраивать» его (обычно на том же Интернет-ресурсе) или оставить себе.

Также не эффективно себя проявила потребительская кооперация совладельцев многоквартирных домов (МКД). Собственники не имеют существенного влияния на расходование собираемых денежных средств УК и ТСЖ, которые, как правило, не формируют систему учета интересов жильцов [4], несмотря на то, что данные юридические лица при продаже своих услуг собственникам МКД тоже позиционируются как организаторы общего потребления ресурсов МКД. На деле УК и ТСЖ диктуют свою волю потребителям. Собрав принудительно (по действующему законодательству) квартплату, им выгоднее быть агентами поставщиков услуг (в том числе выполнять работу своими силами), чем организовывать удовлетворение интересов собрания собственников перед поставщиками услуг. 
Такая система взаимоотношений совладельцев МКД с УК и ТСЖ тоже требует изменения принципов организации совместной покупки собственниками услуг по содержанию и ремонту МКД, а также прочих услуг и ресурсоснабжения дома.

Поэтому кооперации (совместные покупки), помимо экономии средств покупателей, следует акцентироваться на своем дополнительном назначении на организованном выдвижении потребительских требований поставщикам. Для этого целесообразно выделить принятие решения общим собранием потребительского общества в отдельную систему, которая будет определять волю участников, с одной стороны, и являться инструментом формирования организованного спроса, с другой. Подчиненный этой воле агент (кооператив) должен выполнять задание покупателей, заключив соответствующие договоры с поставщиками товаров и услуг.

\section{НЕДОСТАТКИ МАГАЗИННОЙ ТОРГОВЛИ}

Функции потребкооперации как «профсоюза» потребителей и постановщика задач для производителей определяются системными недостатками магазинной торговли. Ниже перечислены основные из них.

1. Чтобы завлечь покупателей, магазину необходимо на прилавке всегда иметь необходимый ассортимент, на котором специализируется магазин [5]. Это означает, что товары должны иметь большой срок годности - как физической, так и моральной. Когда он проходит, товары необходимо выбрасывать. С одной стороны, это убытки, с другой, избыточное природопользование, так как для этого способа торговли производится заведомо больший объем товаров, чем может использоваться людьми. Кооперативный предзаказ не имеет данного недостатка.

2. Широкий ассортимент товаров имеет большое значение для привлечения покупателя в магазин [5]. В итоге, не все товары будут куплены, часть из них отправится на свалку. Покупка по техническому заданию решает данную проблему. Достижение консенсуса в потребительской группе обеспечит возможность серийности производства.

Чтобы победить в конкурентной борьбе при кооперативном сбыте, необходим запас производственных мощностей, технологической гибкости, более быстрой адаптивности к изменениям спроса, а не товаров на складе. Наличие предоплаты на расчетном счету кооператива, подтверждающую готовность покупателя совершить покупку, обеспечит новую инвестиционную активность в реальный сектор экономики.

3. Приемы современного маркетинга побуждают потребителей в магазине делать эмоциональные, рефлексивные покупки, обусловленные личными качествами продавца, красивой упаковкой и прочими иррациональные составляющими. Таким образом, мы, по сути, делаем ненужные нам приобретения.

Покупка по предзаказу, а еще и обсужденная с подобными участниками группы совместной покупки, делает требования к приобретаемым товарам 
несопоставимо более рациональными. Упор на упаковку, составляющую внушительную часть мусорных свалок и доли в цене товара, теряет прежний смысл. Потребности фиксируются техническим заданием - сухим от эмоций документом. Это обеспечит более высокие темпы роста товарного развития и вслед за ним - научно-технического прогресса.

Предзаказ требует планирования личного потребления. Это также снижает личные издержки на покупку ненужного. Однако планирование покупок - это работа. Спонтанное удовлетворение потребностей посредством получения с полки магазина товара избавляет нас от нее. Именно это в сочетании с другой сложной работой по согласованию интересов людей, а так же необходимостью изменения своих привычек, следует отнести к основным причинам, почему более эффективная в экономическом плане система кооперативного потребления не может сама собой возникнуть посредством прямой конкуренции с магазинами.

Для ее внедрения необходимо признать покупку такой же работой, как и создание товаров, и реформировать под эту систему большую часть экономики, выделив на осуществление предзаказа рабочее время. Лучше меньше производить, но делать более полезные товары.

За это время потребкооперация должна сформировать задание производству на ближайший период, обозначить долгосрочные планы. Обсуждение интересов широкого числа потребителей за столом переговоров в группе (а во время самоизоляции - с помощью телекоммуникационных средств) позволит избежать многих скрытых проблем, которые не в состоянии увидеть разработчик [6]. Таким образом, конструкторская деятельность отчасти перемещается с завода в потребительский кооператив для осуществления предпроектной проработки будущих товаров.

Сложная работа по согласованию технических заданий возможна в перспективе, а сегодня можно обойтись простой покупкой тех же самых обыденных товаров, что есть на прилавках магазинов, без дискуссий и сложных систем принятия коллективных решений. Далее на почве возникающих противоречий придется все более и более усложнять систему кооперации.

Очевидно, что это идеальная модель. Полностью организовать потребление по предзаказу очень сложно, но эти отношения можно сделать доминирующими над магазинным способом приобретения. Сегодняшнее разрушение экономических связей с остановкой прежнего производства, вызванной карантинными мерами, с одной стороны, потребует новых приемов ее оживления, а с другой, обеспечит благоприятные условия для реализации кооперативной формы хозяйственных отношений с запуском совершенно новых, гораздо более перспективных, проектов.

4. Высокий уровень монополизации торговли создает проблемы для потребителей, связанные с монопольным извлечением прибыли, ограничение возможности выбора и пр. В противовес бизнесу потребительская кооперация способна создать монопольное потребление. Объединившись в союзы, потребкооперация способна иметь очень крупный масштаб, в том числе международный [1]. 
Целесообразно наделить ее ролью инструмента формирования заявок на объем производства, технические требования и ценообразование товаров, полученные при непосредственном сборе технических и экономических сведений (требований) от потребителей.

Речь идет о преобразовании государственного управления бизнесом в общественное кооперативное с заменой метода влияния государственной власти не на производство, а на характер и объем потребления.

В этом методе реализации управленческих отношений потребитель при поддержке власти влияет на бизнес, а не на власть, опираясь на мнение потребителей, управляет бизнесом напрямую. Таким образом можно достичь более высокого качества самого производства, так как оно будет определяться в большей степени аффилированными представителями потребителя, находящимися в проблемной ситуации, а не чиновниками, являющимися сторонними наблюдателями [7].

5. Качество продукции на полках магазинов, так же как и соблюдение ими убыточных карантинных мер, проверяется в настоящее время не подотчетными потребителям организациями. Они не находятся в проблемной ситуации потребителя, поэтому недостаточно эффективны в плане удовлетворения потребительских интересов [8].

Чтобы интересы покупателей соблюдались, необходимо либо насильственное принуждение со стороны власти, либо влияние потребителей на поставщика. Без применения силы власти осуществление влияния возможно только со стороны крупного покупателя, каковым является потребительская кооперация. В случае высокого уровня коррупции государственные надзорные органы эффективно не работают. Подотчетная своим участникам кооперация справится с этим лучше, однако, вместо коррупции здесь возможно возникновение проблемы «безбилетников» [9], уклоняющихся от оплаты работы организаторов совместного потребления. Эту проблему, являющуюся меньшим злом для граждан, чем коррупция, по-видимому, кооперации придется решать постоянно, применяя различные новые методы, развивая тем самым общественные отношения.

6. Помимо повышения качества потребления кооперация приведет к положительным социальным изменениям. Чтобы достигнуть консенсуса, нужны позитивные межличностные отношения. Они диктуются экономической необходимостью данной формы хозяйствования.

Это значит, что кооперация заинтересована в развитии у людей навыков разрешения конфликтов, в повышении уровня культуры участников, подталкивающих к позитиву по отношению друг к другу [10]. В итоге, можно рассчитывать на улучшение статистики по объему и тяжести преступлений в обществе. 


\section{РАЗВИТИЕ ОТНОШЕНИЙ КООПЕРАЦИИ ПОТРЕБИТЕЛЕЙ С ТОРГОВЫМИ СЕТЯМИ}

Из вышеперечисленного следует, что закрытие магазинов на карантин с массовым переводом общества на кооперативное потребление является не временной мерой, а вложением в формирование новой экономики. После карантина, конечно же, ожидаем некоторый откат к прежнему способу снабжения, но более перспективным является совместное кооперативное потребление граждан.

Форма бизнеса торговых сетей должна измениться. Они могут стать инвестиционными фондами промышленности, находясь рядом и частично оплачивая систему формирования спроса в потребительских обществах и оказывая тем самым свое влияние на него. Предметом инвестиций могут стать новые стартапы, возникающие на почве кооперации. Поскольку у ритейлеров останутся связи с поставщиками, для сохранения и развития бизнеса они смогут инвестировать в их производство, в большей степени подчинив своих поставщиков экономически.

Как уже было обозначено, организацию монопольного микрорайонного потребления целесообразно осуществлять в связке двух кооперативных систем: потребительского кооператива, выполняющего функцию агента потребителей, и территориального общественного самоуправления (ТОС), собственно организующего потребление. На рис. 2 изображена ментальная карта работы TOC в связке с микрорайонным потребительским обществом. Ментальная карта организации микрорайонного потребительского общества приведена на рис. 3.

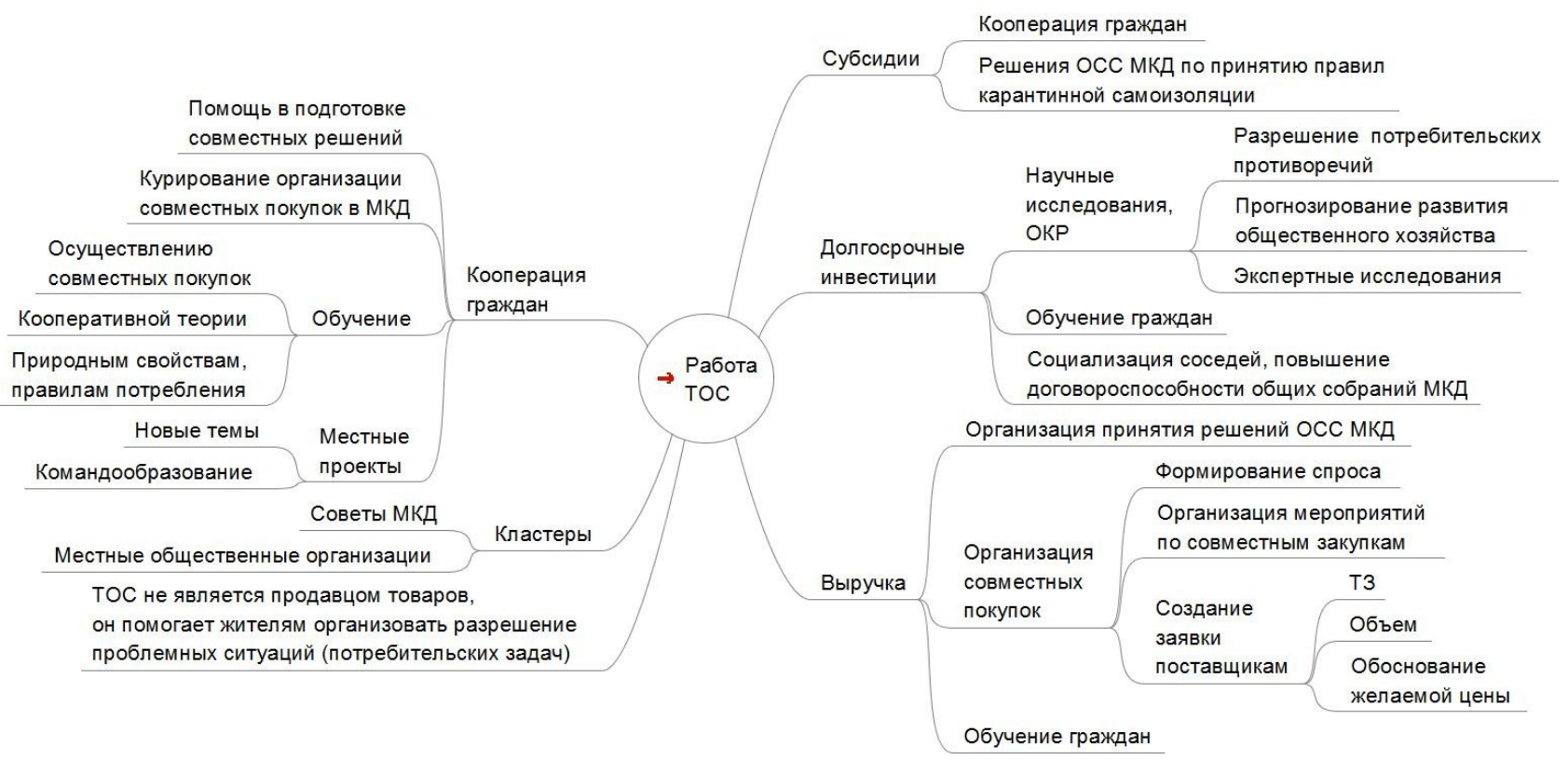

Рис. 2 Организация работы ТОС 


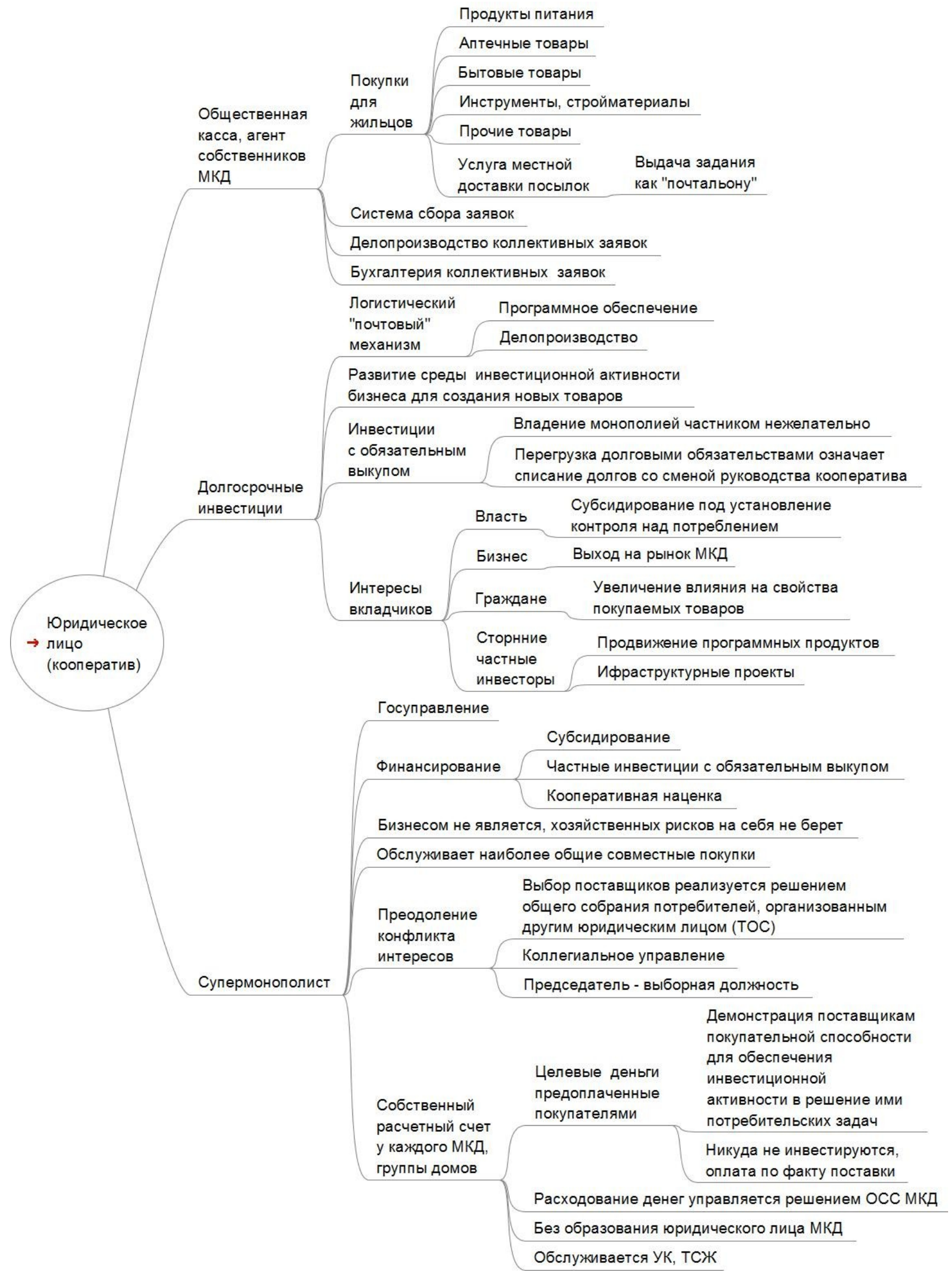

Рис. 3 Потребительский кооператив микрорайона 


\section{ПОТРЕБИТЕЛЬСКАЯ КООПЕРАЦИЯ И САМОУПРАВЛЕНИЕ}

Местное самоуправление подразумевает разрешение общих местных проблем совместными силами граждан. Это ни что иное, как кооперация. Совместное владение многоквартирным домом - это тоже потребительская кооперация, только, к сожалению, многими гражданами не признаваемая. Объединение их в одну систему с кооперативным снабжением продуктами позволит улучшить состояние дел и в сфере ЖКХ.

Радикальное принуждение граждан к принятию кооперативных отношений посредством закрытия продуктовых магазинов вынудит их осваивать кооперативную теорию и кооперативные ценности (являющиеся общечеловеческими: дружба, взаимопомощь, солидарность, честность...) в противовес буржуазно-либеральным (эгоцентризм, экономическая свобода и т.д.). Без этого образования и воспитания кооперация работать эффективно не может, так как она требует принятия солидарной ответственности, а так же достижения консенсуса в сообществах. Для ускорения данного процесса можно принять, поправить соответствующие обязательные стандарты вещания в СМИ (можно многое позаимствовать из советских стандартов, пропагандировавших коллективизм).

Для объединения ЖКХ (жилищно-коммунального хозяйства) с продовольственными закупками можно применить юридические лица УК и ТСЖ. Однако в обществе сформировался очень высокий уровень недоверия к этим организациям. K тому же, их бухгалтерия не способна быстро справиться с задачей проведения огромного числа заявок граждан с большой номенклатурой товаров. И, главное, необходимы поправки в законодательстве для перевода УК и ТСЖ с договора управления на агентский договор и дообучение сотрудников УК и ТСЖ работе в изменившихся условиях отношений с собственниками МКД.

Поэтому целесообразно начать с создания специализированного общемикрорайонного кооператива, который в скором времени делегирует ТСЖ и УК часть своих агентских функций для более активной работы по удовлетворению интересов жильцов МКД. Кооперативу микрорайона по мере развития целесообразно отвести роль союза кооперативов домов.

Система принятия решений общими собраниями жильцов должна быть независима от исполнителей этих решений (ТСЖ, УК, потребительских кооперативов), так как заказчик и исполнитель выполняют разную работу с полярно противоположными интересами в системе кооперации.

Организацию помощи в принятии решений общих собраний собственников (ОСС) МКД (кооперативов) целесообразно реализовывать через юридическое лицо территориального общественного самоуправления. Управление общим имуществом МКД (согласно ЖК РФ) его совладельцы осуществляют посредством решений ОСС МКД. Прочее управление общим кооперативным имуществом (ресурсами) организационно не отличается от управления имуществом ЖКХ. Организация этой деятельности на площадке ТОС совпадает с его целями - реализацией самоуправления граждан, так как 
самоуправление сводится в конечном счете к совместному пользованию какими-то общими ресурсами участников.

Любая человеческая деятельность начинается с принятия решений. Сначала принимается решение, потом осуществляется покупка или выполняется работа. Поэтому согласованное с участниками кооперации решение является первичным продуктом деятельности по организации самоуправления TOC. Далее ТОС передает решение своему агенту микрорайонному потребительскому кооперативу, а тот, в свою очередь, - ТСЖ и УК. Их функция — вести договорные отношения с поставщиками.

Такой сложный алгоритм осуществления покупки вместо простого похода в магазин упрощается нечастым проведением широкомасштабных согласований. Текущая работа кооперации — это сбор и выполнение штатных заявок своих участников. Согласования и новые совместные решения нужны для преодоления противоречий, которые неизменно со временем будут возникать и сообща разрешаться, а так же для реализации инфраструктурных и прочих проектов. В настоящее время это происходит без участия граждан, но данные издержки все равно несут потребители в виде более высоких цен и неудовлетворительного качества товаров и услуг.

Большинство противоречий, как и прежде будет разрешаться без широкого их обсуждения. В процессе подготовки проектов решений общих собраний собственников МКД представители заинтересованных сторон (организаторы кооперации, представители бизнеса и власти) должны приходить к консенсусу. Роль рядовых участников заключается в уточнении проектов решений, в реализации обратной связи производителя с потребителем, власти с гражданами.

Сегодня в УК и ТСЖ осуществляется принудительный сбор денег на обслуживание общего имущества МКД. Поэтому УК и ТСЖ агентами жильцов не являются, воле собственников без содействия власти не подчиняются. Чтобы у совладельцев МКД появилось влияние на неплательщиков за содержание дома, у рядовых участников должна появиться зависимость от решения общего собрания участников.

Если регулярной повесткой общих собраний становится потребление (монопольное) продовольствия и прочих товаров, то его вес резко возрастает. Возможность отключения члена кооперации от системы совместного потребления, в которую включены товары жизненной необходимости, дает власть всему сообществу над каждым своим участником. Уклонение от оплаты содержания товара первой необходимости - жилища - правомерно связать с отказом в праве совершать совместные покупки на продовольствие (товар еще большей жизненной необходимости). Таким образом можно обеспечить реализацию права всех совладельцев на безаварийное содержание дома.

Однако ставить граждан в жесткую зависимость от принятия решения всем сообществом совладельцев МКД недопустимо. Независимо от взглядов у граждан должно сохраняться право на потребление товаров первой необходимости: жилище, продукты питания, медобслуживание, и пр. Поэтому приобретение остальных товаров (не жизненно необходимых) неправомерно 
связывать с жизненно необходимыми. Это оставляет окно для проблемы «безбилетника», но и дает право гражданам иметь более независимую позицию при определении способов потребления и отстаивать свои интересы в вопросах его личного и совместного изменения.

Таким образом снимается государственная полицейская необходимость принуждать вносить «квартплату». Проблема неплатежей «безбилетников» будет решена посредством влияния домашней кооперации. Для тех, кто живет в доме, но снабжается через магазины или соседнюю кооперацию, самообеспечение окажется более дорогим и ниже качеством. Тем, кто сдает в наем жилплощадь, целесообразно подключать своих постояльцев к общедомовому снабжению.

Наименьшая зависимость от внутридомовой кооперации у совладельцев, которые не живут в доме и не сдают жилье. Они должны облагаться только минимальным размером квартплаты, которую правомерно сохранить в виде принудительного платежа, обеспечиваемого средствами государственной власти.

Вложения в средства повышения комфорта проживания осуществляются по принятым общим собранием совладельцев внутридомовым правилам.

Влияние органов власти на УК и ТСЖ целесообразно снизить, направив его на работу ТОС. Управление ЖКХ может осуществляться органами власти воздействием на процесс принятия решений ОСС МКД, опираясь на правила определения последовательности выполнения работ по содержанию и ремонту дома, а также посредством субсидирования кооперации в рамках государственных программ. Таким образом, УК и ТСЖ преобразуются в агента МКД, административно подчиненного ТОС через влияние потребителей и государственной власти.

В экстренном порядке карантинных мер, чтобы существенно сэкономить время и быстрее закрыть магазины для посещения розничных покупателей, целесообразно кооператив микрорайона оснастить быстро доступным программным обеспечением, автоматизирующим процесс работы с заявками на уровне Интернет-магазина. При этом кооператив магазином не является и не должен им быть.

Принятие на начальной стадии бухгалтерских программ и сайта Интернет-магазина позволит сэкономить время на освоение нового ресурса всеми пользователями, уже имеющими навыки работы с подобной системой. Однако далее система отношений с потребителями должна планомерно превращаться в реальную кооперацию с развитием демократии в ней.

По существу речь идет о формировании реального местного самоуправления, управляемого властью посредством влияния на принимаемые в ТОС общими собраниями решения при помощи субсидий и законодательных актов [11]. Государство сможет осуществлять контроль и планирование снабжения, а так же влиять на технологическое развитие, создавая дополнительные привлекательные условия для инвестиций со стороны бизнеса. Это (особенно сегодня) позволит стабилизировать разбалансировавшуюся карантинными ограничениями экономику, взять под управляемый мягкими 
методами контроль подавляющее большинство сфер жизни общества, в том числе позволит повысить эффективность карантинного поведения людей с минимальной необходимостью применять усиление полицейских мер.

\section{ГОРОДСКОЙ ТРАНСПОРТ И ВИРУСОУЯЗВИМОСТЬ}

Сформированная система демократичного управления общественным потреблением позволит реформировать общественный транспорт. В условиях самоизоляции целесообразно сделать так, чтобы в «автобусах» могли одновременно ехать только люди из одной организации. Если они подчиняются ее руководству, то это облегчает реализацию карантинного поведения граждан в общественном транспорте.

Через жилищную кооперацию граждане смогут решить свои бытовые транспортные задачи, предприятиям также будет доступно нанимать «автобусы» для своих сотрудников, чтобы привозить их на работу и развозить после нее по домам. Это означает возможность изменения принципов организации городского транспорта. Вместо маршрутных автобусов будут доминировать заказные автобусы. Во время карантинных ограничений в них можно реализовать эффективные меры против заражения пассажиров под контролем заказчиков поездки.

Современные электронные мультиагентные системы $[12,13]$, проявившие себя эффективно в организации такси, способны оптимизировать пользование имеющимися транспортными средствами. С их помощью можно оптимизировать транспортные расходы: прокладывать маршруты с пересадками, согласовывать пути перемещения по дорогам, синхронизировать движение машин и т.д. Трамваи, троллейбусы и метро могут утратить свое прежнее назначение.

Эта система организации транспорта способна облегчить дальнейшее развитие движения машин по дорогам посредством роботизации, усовершенствования городской логистики со снижением числа транспортных задач для потребителей. Она же обеспечит сокращение и в дальнейшем ликвидацию пробок на дорогах, а также уменьшит нагрузку на дорожное полотно. Изменится сама постановка задачи для производителей машин, автобусов и прочего транспорта, что даст новый импульс для инвестиционной активности в эту отрасль.

Следует акцентировать внимание на том, что чем меньше потребности в перемещении людей, тем это удобнее гражданам, и тем меньше распространение инфекции. Локализация работы (временной и постоянной) неподалеку от дома, внутри микрорайонного сообщества поможет решать и задачу занятости [14], и ограничения распространения инфекции.

Снижение потребления машин сокращает доходы автотранспортной и сырьевой отраслей. Принятие политики власти, направленной в первую очередь на удовлетворение интересов граждан (потребителей), а не бизнеса, облегчит преодоление консерватизма производителей товаров. 


\section{ОТ ИНДИВИДУАЛИЗМА К КОЛЛЕКТИВИЗМУ}

Необходимость спасения людей карантинными методами обнажает старый спор между индивидуалистами и коллективистами $[15,16]$, дает новую дополнительную аргументацию в пользу коллективизма.

Для предотвращения распространения инфекции, нужно обеспечить условия, чтобы можно было избежать встречи в одном месте случайных людей, с одной стороны, а с другой - иметь возможность влиять на всех людей, где бы они не находились. Это позволит локализовать эпидемию.

Повсеместный контроль и подчинение входят в разрез с либеральными идеалами личной свободы граждан. Однако когда речь идет о физическом выживании (эпидемии возможны и хуже, чем коронавирусная), то данный принцип общего блага не несет. Таким образом, коллективистский идеал «Любовь, Дружба, Взаимопомощь», обслуживающий совместные общественные интересы, более универсален, чем либерально-буржуазный идеал «Свобода», основанный на личных интересах.

Современная техническая реализация контролирования людей электронными методами доступна и достаточно быстро (но не мгновенно, как требуется) реализуема. Однако «чипование» в высоко централизованном обществе, управляемом не демократичными методами, или буржуазном, управляемом по принципу естественного отбора и доминирования торговых интересов (а не гуманистических), может принести много вреда гражданам. Помимо этого, реализация электронного проекта борьбы с эпидемией доступны не всем странам по материальным и технологическим причинам. Пообщинное разделение людей возможно даже в самых материально слаборазвитых обществах.

В децентрализованном демократическом обществе можно обойтись и без дорогостоящего «чипования» посредством сетевого контроля людьми друг друга, осуществляемого на принципах товарищества и взаимопомощи с возможностью взаимного влияния на членов группы (не требующих специальных инвестиций). В том случае, если без него технически не обойтись, то электронный контроль принесет меньше вреда участникам, поскольку основное внимание будет уделено разрешению самой проблемы, а не открывающимся дополнительным возможностям применения власти и контроля.

Солидарная групповая ответственность за каждого участника всеми членами группы способна решить проблему ограничения распространения вирусной инфекции. При появлении заражения внутри группы, на нее накладываются дополнительные ограничения на внешнее личное общение. Этот принцип позволяет применять режим повышенного жесткого контроля и ограничений не для всего общества, а только для его частей, в которых обнаружена инфекция.

Вирусоуязвимость системы ограничивается кластерностью сети социальных связей людей. Речь идет не только о решении биологических проблем. Чем более замкнуты сообщества, тем меньше скорость 
распространения не только болезней, но и товаров, информации и пр. Поэтому абсолютной системы отношений «на все времена» создать не удастся, социальные и технологические формации будут меняться по мере поступления, накопления новых проблем.

\section{ЗАКЛЮЧЕНИЕ}

Предлагаемые в данной статье меры, направленные на достижение нулевого распространения коронавирусной инфекции, обеспечат возможность решить не только проблемы с распространением инфекции, но и дать новый импульс для развития экономики. Они достаточно сложны и сильно меняют имеющийся уклад жизни.

Кооперативные реформы торговли, ЖКХ и транспортной системы позволят оживить инвестиционную активность даже в условиях карантина. Можно так же рассчитывать на то, что появление веры в способность полностью остановить распространение вирусной инфекции повысит самодисциплину граждан в плане соблюдения режима самоизоляции. Также этому будет способствовать рост взаимного влияния друг на друга соседей по МКД, людей в других сообществах. В итоге повысится уровень эпидемиологической защищенности общества.

Сегодня необходимо совершить радикальный поворот в сторону коллективизации экономики. Отъем имущества и массовое принуждение к обобществлению при этом не предусматривается. Наоборот, преследуется цель смягчения режима чрезвычайной ситуации и развития конструктивных отношений общества с бизнесом и властью.

Изменение способа торговли и распределения товаров позволит улучшить качество потребления и повысить эффективность работы предприятий за счет выдачи им заданий, осмысленных в групповых обсуждениях, потребителями. Система обслуживания домов, подчиненная воле потребителей, обеспечит значительное повышение темпа роста комфортности проживания в них. Реформирование транспорта под управляемое коллективное потребление решит проблему пробок, плохого состояния дорог и высокого энергопотребления, а так же экологического состояния городов, связанных с эксплуатацией машин.

Прежний образ жизни и система общественного управления утрачиваются и ломаются каждыми новыми вынужденными противоэпидемическими мерами. Нарастающий на почве разрыва прежних социальных связей экономический кризис тоже вносит свои коррективы. Очевидно, что меры противодействия угрозам будут тем радикальнее, чем выше вероятность потерь большого числа людей. Поэтому целесообразно не дожидаться худшего сценария развития событий и принять эффективные меры предотвращения распространения инфекции и формирования новой экономики, примирившись с достаточно непривычным для современного человека коллективным стилем жизни. 


\section{ЛИТЕРАТУРА}

1. Сахарова Д.Б., Котов И.С. История и теория кооперативного движения: учеб. пособие. Минск: Новое знание, 2005. 248 с.

2. Ивашкин М. В., Колесников А. В. Совместная покупка как экономическая категория и рынок совместных покупок в информационном обществе // Вестник Тихоокеанского государственного университета. 2019. №2(53). С.55-62.

3. Костина С. Е. Правовая природа совместных покупок // Вестник Саратовской государственной юридической академии. 2015. №4 (05). С. 44-47.

4. Норин А.В. Договор с управляющей организацией как договор подчинения URL: https://cyberleninka.ru/article/n/dogovor-s-upravlyayuscheyorganizatsiey-kak-dogovor-podchineniya (дата обращения: 30.04.2020).

5. Seiler S. The impact of search costs on consumer behavior: A dynamic approach // Quantitative Marketing and Economics. 2013. № 11(2). P. 155-203.

6. Моисеева Т.В. Проблемы интерсубъективного управления инновационным развитием социотехнических объектов // Вестник СамГТУ. Серия "Технические науки". 2017. № 3(55). С. 16-31.

7. Vittikh V.A. Introduction to the theory of intersubjective management // Group Decision and Negotiation. 2015. № 24(1). P. 67-95.

8. Моисеева Т.В., Поляева Н.Ю. Моделирование проблемной ситуации в теории интерсубъективного управления // Вестник Дагестанского государственного технического университета. Технические науки. 2018. № 45(1). C.160-171.

9. Остром Э. Управление общим. Эволюция институций коллективного действия; пер. с англ. Т. Монтян. Киев, 2013. 400 с.

10. Мятишкин Ю.В. Средства достижения консенсуса в широких группах людей, объединенных общей проблемной ситуацией // Проблемы управления и моделирования в сложных системах: труды XIX Междунар. конф. - Самара: Изд-во ООО «Офорт», 2017. С. 338 - 345.

11. Мятишкин Ю. В. Формирование системы управляемого самоуправления в многоквартирных домах. PREPRINTS.RU. URL: https://doi.org/10.24108/preprints-3112029 (дата обращения: 30.04.2020)

12. Виттих В.А., Моисеева Т.В., Скобелев П.О. Принятие решений на основе консенсуса с применением мультиагентных технологий // Онтология проектирования. 2013. №2. С.20-25.

13. Скобелев П.О., Майоров И.В. Мультиагентные технологии в интеллектуальных системах управления ресурсами в реальном времени // Морские информационно-управляющие системы. 2015. №1(7). С. 2439.

14. Мятишкин Ю. В. Усиление карантинных мер от коронавируса и оживление экономики посредством реформирования системы ЖКХ // Экономическая политика и ресурсный потенциал региона: сб. статей III Всерос. науч.-практ. конф.с междунар. уч. - Брянск: Брян. гос. инженерно-технол. ун-т, 2020. C.99-104. 
15. Пискорская С. Ю., Летунова О.В. Стандарты социальности индивидуалистичекого типа общества // Вестник Сибирского государственного аэрокосмического университета им. академика М.Ф. Решетнева. 2006. №3 (10). C. 131-135.

16. Пискорская С. Ю. Коллективистский тип общества и его стандарты // Вестник Сибирского государственного аэрокосмического университета им. академика М.Ф. Решетнева. 2006. №3 (10). С. 126-131.

\section{REFERENCES}

1. Sakharova D. B., Kotov I. S. History and theory of the cooperative movement: studies manual. Minsk: Novoe Znanie, 2005. 248 p. (In Russian).

2. Ivashkin M. V., Kolesnikov A.V. Joint purchase as an economic category and market of joint purchases in the information society // Bulletin of the Pacific State University. 2019. No2(53). 55-62. (In Russian).

3. Kostina S. E. Legal nature of joint purchases // Bulletin of the Saratov State Law Academy. 2015. No 4 (05). P. 44-47/ (In Russian).

4. Norin A.V. An agreement with a management organization as a subordination agreement // Modern Science. 2015. URL: https://cyberleninka.ru/article/n/dogovor-s-upravlyayuschey-organizatsiey-kakdogovor-podchineniya (accessed: 30.04.2020) (In Russian).

5. Seiler S. The impact of search costs on consumer behavior: A dynamic approach // Quantitative Marketing and Economics. 2013. No. 11(2). P. 155-203.

6. Moiseeva T. V. Problems of intersubjective management of innovative development of sociotechnical objects // Bulletin of Samara State Technical University. Series "Technical Sciences". 2017. No. 3(55). P. 16-31. (In Russian).

7. Vittikh V.A. Introduction to the theory of intersubjective management // Group Decision and Negotiation. 2015. No. 24. Issue 1. P. 67-95.

8. Moiseeva T. V., Polyaeva N. Yu. Modeling of the problem situation in the theory of intersubjective control // Bulletin of the Dagestan State Technical University. Technical science. 2018. No. 45(1). P. 160-171. (In Russian).

9. Ostrom E. General Management. Evolution of institutions of collective action; transl. from English T. Montyan. Kiev, 2013. 400 p.

10. Myatishkin Yu. V. Means of achieving consensus in broad groups of people united by a common problem situation // Problems of management and modeling in complex systems: proceedings of the XIX international conference. Samara: publishing house "Ofort", 2017. P. 338-345. (In Russian).

11. Myatishkin Yu. V. Formation of a system of managed self-government in apartment buildings. PREPRINTS.RU. URL: https://doi.org/10.24108/preprints3112029 (date accessed: 30.04.2020). (In Russian).

12. Vittikh V. A., Moiseeva T. V., Skobelev P. O. Decision-making based on consensus using multi-agent technologies // Ontology of Design. No. 2. 2013. P. 20. (In Russian). 
13. Skobelev P. O., Mayorov I. V. Multiagent technologies in intelligent resource management systems in real time // Marine information and control systems. 2015. No. 1(7). P. 2439. (In Russian).

14. Myatishkin Yu. V. Strengthening of quarantine measures against coronavirus and reviving the economy through reforming the housing and utilities system // Economic policy and resource potential of the region: Collection of articles of III all-Russian scientific-practical conf. Bryansk: Bryansk State Engineering and Technology University. 2020. P. 99-104. (In Russian).

15. Piskorskaya S. Yu., Letunova O. V. Standards of sociality of individualistic type of society // Bulletin of the Siberian State Aerospace University named after ac. M. F. Reshetnev. No. 3 (10). 2006. P. 131-135. (In Russian).

16. Piskorskaya S. Yu. Collectivist type of society and its standards //// Bulletin of the Siberian State Aerospace University named after ac. M. F. Reshetnev. No. 3 (10). 2006. P. 126-131. (In Russian).

\section{СВЕДЕНИЯ ОБ АВТОРАХ}

Мятишкин Юрий Владимирович - старший инженер, Институт проблем управления сложными системами Российской академии наук обособленное подразделение Федерального государственного бюджетного учреждения науки Самарского федерального исследовательского центра Российской академии наук, г. Самара, Россия, myat yv@mail.ru

\section{ABOUT THE AUTHORS}

Myatishkin Yuri Vladimirovich - senior engineer, Institute for the Control of Complex Systems of the Russian Academy of Sciences, Samara, Russia 